\title{
Educating dentists - the value of the research environment
}

\author{
P. Glantz'
}

\begin{abstract}
I hope, ladies and gentlemen, that you agree with my opening statement that 'during the immediate past century, a dramatic improvement of oral health and dental status occurred on a world wide basis.' In my opinion, the combined efforts from dental educators, dental researchers and dental clinicians have, without doubt, been the actual initiators and generators for this improvement working along the traditions of dental scientists such as Sir Wilfred Fish.
\end{abstract}

I will try to present examples to demonstrate this statement later in my presentation, but first we should perhaps make sure that we agree on the definition of the word 'education' and the word 'research'. In my mind we should accept the liberal ones offered by the Oxford English Dictionary. Therein education is defined as The systematic instruction, schooling or training the young (and, by extension, to adults). Research is, on the other hand, defined as The act of searching for specific answers to problems. Acceptance of these definitions leads to the immediate acknowledgement of education and research as processes that have been going on together for a very long time in dentistry.

\section{Early dental research}

The systematic search for and transfer of increased dental knowledge seems to have started so long ago that today we are not aware of the names of the early dental researchers and educators. Those, for example, who in the valley of lower Mesopotamia, some 5000 years ago, reported in cuneiform writing in one of the surrounding clay tables that toothache is caused by the gnawing of small worms in the aching tooth.

Other examples of early, today unknown, dental innovators, who also acted as educators, include the Chinese practitioners, who thousands of years ago reported that acupuncture could be used for treatment of

${ }^{*}$ Text of the 17th Wilfred Fish Lecture presented to the General Dental Council on March 222000.

${ }^{1}$ Professor P. Glantz, Vice Chancellor, Malmö University, Sweden.

(c) British Dental Journal 2000; 189: 241-246

\section{It is also interesting to note that many of today's dental materials and treatment methods were developed and described a very long time ago}

toothache and other cases of oral pain.

The Egyptian Papyrus Ebers - the most important medical papyrus from about $1500 \mathrm{BC}$ - and the Assyrian tablets from about $670 \mathrm{BC}$ are other examples of early dental educational reports on research matters, as are the papers of Greek scientist Hippocrates, who lived between 460 and 375 BC.

Hippocrates, who is frequently referred to as 'the father of medicine' attached special interest to the diseases of the dental system in many of his 'textbooks'. He gave suggestions for proper dental treatment, and it is particularly interesting to note that he considered afflictions of the teeth to be dependent on:

'A combination of natural predisposition and the corroding action of accumulated filth.'

Dental problems obviously played significant roles in many peoples lives in olden days, and we can follow frequent descrip- tions of these problems and suggestions for their proper professional treatment in the literature through the centuries with a clear focus on dental caries and toothache. Additional aspects of dentistry were, however, also covered. As this is not primarily a historical presentation, I will only mention that the first description of artificial teeth was made by the Roman poet Martial, who, in a poem, indicated that artificial teeth were fashionable in Roman society. We should also remember that so-called 'cosmetic dentistry' is not a new invention at all. The Maya Indians, who placed inlays of jade and turquoise in the buccal surfaces of maxillary front teeth, practised this particular type of treatment.

As we follow the relationship between dental research and dental education during the centuries, it is also interesting to note that many of today's dental materials and treatment methods were developed and described a very long time ago. A material with a basic composition similar to that of dental amalgam, for example, was first reported by the Chinese more than 1300 years ago, and a set of dental scalers with the basic modern design of similar modern instruments was described about 900 years ago by the Arabian surgeon Abulcasis. In the sixteenth century the famous French surgeon Ambroise Paré also spoke of the transplantation of teeth. At least some types of dental education have therefore been associated with 'dental research' for as long as we know.

\section{An independent field}

As the health service sector was slowly developing, dentistry achieved recognition as a specialised field. The first sign of an independent field of dentistry appeared in eighteenth century Western Europe. The Frenchman Pierre Fauchard, who lived between 1678 and 1761, has long been recognised as the first modern dental technician, educator and researcher. In his famous textbook of 1728, entitled $L e$ chirugien Dentiste our traité des dents, he presents an excellent description of teeth and the alveolar processes. Fauchard is further credited with having introduced the 
term dental caries and he definitely put aside the story of 'worms'. Instead, he stated that 'the little or no care as to the cleansing of teeth is ordinarily the cause of the maladies that destroy them.' The influence of Fauchard on the evolution of almost every aspect of dentistry has been so far-reaching that he has significantly been styled 'the father of modern dentistry.'

Around the middle of the nineteenth century, knowledge about dental diseases and their treatment had reached such levels that the first independent academic dental educational institution, The Baltimore College of Dental Surgery, was chartered by the state of Maryland. The course of study lasted two years in those days - the same amount of time required for a medical degree with instructions during four months of the year. The remainder of the time was spent receiving practical experience in a dental office.

As a result of the successful foundation of the Baltimore school several similar centres were soon founded in Western Europe and the United States. In the UK pioneering centres for dental education were located in Liverpool and Birmingham, where the doors to undergraduate students first opened in 1860 and 1869 respectively. Even if there are very few indications of the systematic dental research activities in the early dental institutions, the mere fact that they were accepted as academic institutions indicates that they must have had some contact with existing research and development.

It should be remembered that when dentistry began to be practiced by graduates of the new academic centres in the major cities, in other parts of the world dental treatments were performed - and are, to a limited extent, still performed — by poorly qualified operators. In the early days these operators were often jack-of-all-trades who declared that they, for example, also bled and made powder for itch. Later they unfortunately tended to focus their activities on more lucrative clinical dental procedures for which they had no proper, research-based, training.

From its emergence as an autonomous health care sector in the mid-1800s,

\section{From its emergence as} an autonomous health care sector in the
mid-1800s, dentistry
rapidly developed as a
mainly surgical health
profession.

dentistry rapidly developed as a mainly surgical health profession. The reason was the overwhelming prevalence of oral diseases, in combination with a lack of detailed understanding of the aetiologies, but knowledge about available surgical techniques.

Most of dental research in the 1800s was also focused on technical and surgical aspects. This presence in dentistry of an abundance of minor surgical and technical treatment problems and treatment techniques, is probably one of the reasons that we have seen and continue to see so many attempts to treat dental problems with nonresearch based, crude technical approaches.

\section{The first dental scientists}

Fortunately, some particularly important progress in dental research that gradually changed the character of dental education occurred around the turn of the twentieth century through contributions from a line of dental researchers and educators that were graduates of the new academic Dr Willoughby D Miller (1853-1907), the American discoverer of the chemibacterial cause of caries. He originally went to Berlin as part of his postgraduate basic science education to follow lectures given by some of the leading international natural scientists of those days. There he became interested in dentistry, and went back to the US to receive his basic dental training at Michigan. He returned to Germany thereafter, and spent many years as a Professor of Operative Dentistry at the University of Berlin, teaching generations of undergrad- uate dental students about the latest results of dental research. Sadly Dr Miller died prematurely of peritonitis, when he was in the process of returning to a dental school deanship in his native United States.

Another of the great early dental researchers and educators was Dr Greene Vardiman Black (1836 - 1915). Dr Black is recognised by many as the outstanding dental scientist of the nineteenth century. Black's interest and research covered the entire field of dentistry. His work not only contributed to the standardisation of tooth cavity preparations - for which he is best remembered today - but he also showed great interest in what is today known as the field of preventative dentistry. Through his lectures first at the Missouri Dental College in St Louis and later for a longer period at Northwestern University School of Dentistry in Chicago, Dr Black made a strong impact also as an educator. He thereby set an example of the importance of combining research and education in dental schools.

Sir Wilfred Fish $(1894$ - 1974) was a scientist of the same mould although active during a somewhat later period. He, however, still made an enormous impact not only in this country but also in the international dental arena. Like many of his fellow clinicians, educators and researchers with a broad education and clinical interest, it is typical that Sir Wilfred's contributions to the dental literature carry such vastly different titles as Principles of Full Denture Prostheses, Experimental Investigations of the Enamel, Dentine and Dental Pulp; Paradontal Disease; and Surgical Pathology of the Mouth.

The research contributions from the above scientists and their many colleagues systematically increased our knowledge of the biology of the oral cavity, as well as of the oral diseases, their diagnosis and treatment. Their subsequent educational initiatives led to major research-based impacts on the dental profession. Early strong links were thus built between dental research and both undergraduate and postgraduate dental education. As a consequence, I believe it to be both correct and fair to state that, in terms of clinical relevance, few areas of 
research have been more successful than dental research, at least not in the health sector. This strong, almost instant impact from research could hardly have taken place if there had not been these viable links between dental research and dental education.

The complexity of dentistry as a clinical health service gives rise to demands on dentists to combine profound academic knowledge with high clinical skill. At times it was almost inevitable that the ability of the dental profession to adequately control treatment quality would be questioned professionally and publicly. A typical example of such an event was the attack by Sir William Hunter, who around 1910 accused dentistry of causing sepsis in many patients. Other more recent examples are the incidents when attacks have been made against the dental profession for causing systemic as well as systematic intoxication of the public through dental materials such as dental amalgams and composites.

\section{Accusations and challenges}

Within the dental profession a range of early actions were taken to meet such accusations and challenges in a constructive fashion. One of the earliest reviews to emphasise the importance of essential links between dental education and dental research was made in the United States in 1926 in the so-called Carnegie Report. This report was written by a biochemist, Dr W J Giles, who was one of the founders of the International Association for Dental Research, and the first editor of the Journal of Dental Research. In the Carnegie Report he presented a plan that resulted in a complete reorganisation of dental education first in the United States and Canada and later in many other countries.

The four years that Dr Giles spent in preparing the report led him to conclude not only that dental education must be associated with and based on dental research but also that dentistry, as a health profession, ought to remain separate from conventional medicine. Nevertheless, he predicted correctly that dentistry must and would develop into a health service equal to medicine. In this context I believe it to be appropriate to quote Dr Giles conclusion from the mid 1920s that: 'I am hopeful and confident that the day is not far distant when dentistry, freed from the demoralising trade dominance that has held it back from its highest professional attainments, will be universally accorded the full degree of respect and regard that is due to every branch of the arts and science of medicine.'

\section{There is overwhelming evidence in favour of close association between dental \\ research and dental education.}

\section{The General Dental Council}

The General Dental Council is in itself another appropriate example of a systematic action that was taken in this country over 40 ago to provide quality control of dentistry and ethical guidance to dentists.

The role of the GDC in education and training dentists is therefore central to its statutory regulatory framework. On the international level we can perhaps find other countries, for example my own, where there are also regulatory bodies for the dental profession. Unlike this country, however, the responsibility is shared between professional bodies and government agencies. To my mind, you are most fortunate to be able to handle and negotiate important professional matters in one council.

To sum up the situation described, there is overwhelming evidence in favour of close association between dental research and dental education. If we pick just one single example of the impact of dental research, and the benefits of the close connections between dental research and dental education, the best known and longest lasting one is perhaps related to the research findings by Dean and co-workers. In the early 1940s Dean and his group first observed that an inverse relationship exists between the concentration of fluoride in the drinking water and dental caries in children. This finding, which from an epidemiological point of view is rivalled by few achievements in modern medicine, was followed by the now classical trials at Grand Rapids in the state of Michigan. The trial showed a 50\% reduction of tooth decay in children from that city after fluoride was added to the drinking water supply.

To my mind it is evident that well established connections between dental research and dental education generated and facilitated the distribution and understanding of the early research reports on the relationship between the water fluoride concentration and caries. Thus, in this country and around the world where dentists were educated in research environments, the use of fluoride in drinking water, rinsing solutions, varnishes and toothpaste began to have a major, almost immediate, impact on the prevalence of dental caries. In these countries a situation has now been created where the caries disease among children has been so greatly reduced that often more than half of them and sometimes even more have permanent dentitions that are caries-free. In parts of the world, however, where there is little or no link between dental education and international dental research, reduction of caries is often non-existent or has developed at a lower level and a slower rate.

In a presentation such as this one, it is not possible to cover all the major steps in the systematic improvement of dental education and its dependence on the research environment. The recognition that plaque bacteria can initiate gingivitis, which can progress to periodontal disease, and the development of modern implant and adhesive dentistry should, however, be mentioned as they are all highly clinically significant and in the process of opening new avenues in dental education.

Taking the field of modern restorative dentistry as a good, recent example of the benefits of education in a research environment, there are few successful modern clin- 
ical sectors. In replacing capping, crowning, varnishing, sealing, bonding and otherwise linking of living and non-living materials in the oral cavity, dentists today repeatedly attain functional adhesive joints that can resist extremes of temperature, force, and reactive chemistry for useful periods of enormous benefit to those who seek their services. This is done through a practical, clinical knowledge of, and respect for, in this case the basic principles of adhesion science, which could not have been achieved without a basic education in a research environment.

\section{Postgraduate dental education}

It is not possible to discuss the significance of the research environment to dental education without also mentioning something about postgraduate dental education, as this type of dental education takes so many more forms than undergraduate education. Simple statements are not possible to make. If again we begin by looking back, it is evident that most of the postgraduate dental education in the early days was carried out by the manufacturers of dental products.

A prominent member of that group was Dr Samuel S White of Philadelphia (18221879), who founded the once-famous SS White Dental Mfg. Co. The original close connections between dental postgraduate education and the dental industry are illustrated by the fact that Dr White was not only the leader of a major dental manufacturing company, but also publisher of Dental Cosmos, the once-leading international dental journal that merged with the Journal of the American Dental Association in 1936.

With the development of modern academic dentistry, direct associations between industry and dental postgraduate education have become less frequent. We should, however, recognise that as modern dentistry was branching out, parts of dental research, and thus also postgraduate education, stayed with some manufacturers of products. This is particularly the case for certain areas of dental materials and pharmaceuticals.

Even if most types of postgraduate dental education may be without direct industrial ties, many are still very commercialised.

\section{Private enterprise is there primarily to try to prove the effectiveness of a commercial product or a commercial technique as quickly and accurately as possible, while academicians are seeking — or at least are supposed to seek knowledge.}

The funding situation for postgraduate dental education is therefore in many ways of key importance and vastly different from that influencing undergraduate education. Even if the aim of the presentation is to discuss the influence of the research environment, it should be mentioned here that the difficult funding situation for postgraduate dentistry could create situations where potential ethical compromises are imminent.

The ethical problems that I have in mind are generated by the fact that members of the universities and private enterprise, eg private practice or industry, come to cooperative postgraduate situations and seminars with somewhat different objectives. Private enterprise is there primarily to try to prove the effectiveness of a commercial product or a commercial technique as quickly and accurately as possible, while academicians are seeking — or at least are supposed to seek - knowledge. It is to be expected that such a difference in fundamental objectives will create a range of ethical problems. Penetration of these problem-complexes is one of the most important aspects of ongoing discussions in academic dentistry.

Another important and related issue is the realisation that as research produces many changes over the lifetime of a dentist, a continuum of education is necessary for our patients to benefit from research. Without continuing education programmes dentists of my own generation would, for example, not have been able to handle composite filling materials in a proper way nor would they have been able to place osseointegrated implants. Academic dentistry and regulatory bodies such as the GDC therefore have a mutual responsibility to create and maintain strong, long-lasting and active research environments also for postgraduate dental education.

In conclusion, the transitions of the dental profession that took place during the immediate-past century would not have been possible if the impact of dental research had not been strong, continuous, and efficient.

\section{Looking to the future}

To meet future goals, the ties between dental education and dental research must therefore not only be maintained but also further broadened and strengthened eg through the application of a holistic teaching view and use of research oriented educational methods such as PBL (Problem-Based-Learning). Such actions are presently taking place in many parts of the world. In order to support them, several national and international associations for dental education have recently been founded and the International Association for Dental Research has also established a special Educational Research Group.

If we look to the future, many dental educators and researchers have pointed to a range of immediate educational challenges and consequences of modern dental research. At the School of Dentistry of the University of California, San Francisco, a group of researchers have for example recently concluded that:

Schools that limit research activities too rigidly to short-term applications towards what are perceived to be 'oral' problems will often miss exciting opportunities for the kind of multidisciplinary, 
interprofessional, and collaborative team research that is most likely to solve the complex challenges presented by oro facial disease and disorders.'

Along these lines we can foresee a closer future relationship not only between dental research and dental education but also between dentistry and its allied disciplines.

Here, it is again important to note that there is more than one allied discipline to dentistry. Medicine is the most important one with traditionally close relationships with most clinical dental subjects, for example, with oral and maxillofacial surgery, oral medicine, and periodontology. For clinical subjects such as prosthetic dentistry and restorative dentistry, nonmedical disciplines such as engineering and natural sciences have, however, traditionally been of equal or under certain circumstances even of greater significance. In recent years, the increased importance of the social aspects of dentistry has also highlighted both the needs for research connections and educational ties between dentistry and the social sciences.

\section{Retaining independence}

With this situation in mind the arguments of Dr Giles from 1926 are still valid. It is thus understandable when academic dental units prefer independence to sometimes tempting mergers with medicine and medical research. This does not mean that I am in opposition to a dental school becoming a special, independent unit of subfaculty, for example, within a larger health care faculty or an expanded Faculty of Medicine. Such reorganisations are sometimes necessary particularly to reduce overall administrative costs. What I am aiming at is that, bearing the complex basic science background of dentistry in mind, it is important that dentistry remains an independent clinical field - a field that is able independently to control its own education and research and to seek research collaboration with other scientific disciplines. In spite of its sometimes relatively moderate size, academic dentistry must thus in my mind not be organised as just another unit, for example within a classic faculty of medicine. In the event that such a transition should take place, I am afraid that, with time, academic dentistry is likely to lose many of its presently fruitful associations with allied, non-medical disciplines.

In the future I am afraid there will be risks of losing our academic and financial independence, and there will be other challenges to dentistry, dental education and dental research. All health service practices, both educational and clinical, will be profoundly affected in this new century by:

1 The ageing of our society,

2 The need to continually address the issue of cost,

3 The necessity to deliver health care in a co-operative environment, and

4 The impact of research findings on our

It is important that dentistry remains an independent clinical field - a field that is able independently to control its own education and research and to seek research collaboration with other scientific disciplines.

basic understanding of human disease and disease management.

How closely events in dentistry will parallel general changes in the health science sector remains to be determined. Irrespective of the outcome, however, a constant factor in health education and clinical practice is that at the end of the line there is a patient with real and personal needs. Patient contact thus continues to be a major factor in both dental education and dental research.
Regardless of the imperative, however, no change will be easy, as academic dental research environments encompass the entire complexity of the university structures. They have the multiple missions of a faculty — including education, patient care, independent or semi-independent clinical practice, research, and community service - set against rapidly changing public expectations, as well as continuing government and private pressure on costs.

This complexity leads us to another of the current problems of the research environment, ie the apparent lack of correlation between how knowledge is requested and used in a modern society and the way in which knowledge transfer is organised in the academic world. It is thus a true paradox that universities and other higher institutions of learning, which we all rely on for renewal and transfer of our common pool of knowledge, are so old-fashioned from organisational points of view. In a way they are presently reflecting the structure of knowledge at the end of the nineteenth century than that of today. To make sure that dental education is in tune with the nature of modern dentistry, it will therefore be increasingly essential for dental education to establish close and fruitful dialogues, not only with dental research, but also with organisations such as the General Dental Council.

Another serious problem that is emerging in dental education and dental research, as in other sections of the academic world, is that our competitiveness is being slowly undermined by difficulties for universities and colleges to recruit and retain bright minds. In the 1999 November issue of The Times Higher Education Supplement, Sir John Kingman, Vice-chancellor of Bristol University stated for example that 'unless urgent action is taken to improve academic pay and conditions, the United Kingdom world class science base will suffer irreparable damage.' In his article Sir John further states that even if fostering of excellence in our science base is a prerequisite for economic success, universities and colleges could presently not offer attractive pay and work conditions. In the future, he therefore fears that universities will not be able to recruit 
and retain top scientists into academic posts. In academic dentistry these problems are well known - in my country, in this country and in many other parts of the western world.

A further problem that dentistry shares with medicine and many other sciences is that many senior academic teachers will retire within the next decade. The 1999 December issue of the Times Higher Educational Supplement, for example, reports that medical schools in this country face a crisis recruiting top researchers to clinical chairs. The article in question reveals that an unpublished survey indicates that at least 74 of the 401 established chaired positions in the United Kingdom are presently vacant.

Dentistry is undoubtedly facing such problems. In our field the problem is aggravated by the recent loss of several senior positions, primarily by underfunding. Unless considerable changes are made, at least in my country, it is therefore questionable if in the future we will be able to maintain strong research environments in our

\section{Unless considerable changes are made, at least in my country, it is therefore questionable if in the future we will be able to maintain strong research environments in our dental schools}

dental schools - the research environment needed to maintain the present high quality dental education. Changes also have to be made in such a way as to dramatically reduce the present burden placed on clinical chairpersons to meet the conflicting demands of their local health authority and the university. It is presently easy to understand that so many bright young graduates are put off an academic career by the combination of the high work pressure, increased administration, low income compared to alternative employment in practice or industry, and the demands of clinical practice that faces them if they accept.

\section{Conclusion}

Summing up this presentation, there is overwhelming evidence that dentistry as a health service profession has benefited enormously from the education of dentists having taken place in a productive research environment. In years to come I am sure that this marriage between education and research has to meet many challenges. I do hope that our society will continue to consider it worthwhile to maintain it, as I believe that the quality of the services that we are offering to our society is to a great extent dependent on strong ties between dental research and dental education. 